\title{
Building a Model of the Modern Innovative Management System of an Educational Establishment
}

\author{
Vorontsova L.V.a \\ Safiullin N.Z.b \\ Fukin I.A.c \\ Timiryasova A.V. $^{d}$ \\ acd Institute of Economics, Management and Law, Kazan, Russian Federation, 420111 \\ ${ }^{b}$ Kazan Federal University, Institute of Management, Economics and Finance, Kazan, 420008, Russia
}

\section{Doi:10.5901/mjss.2015.v6n1s3p204}

\begin{abstract}
The work is devoted to building a model of the modern innovative management system of an educational establishment. The necessary prerequisites and objectives of the system introduction, as well as its key characteristics, are defined. The results of introducing the elements of the system in the functioning educational establishment are presented.
\end{abstract}

Keywords: information system model, information management system, educational establishment, transaction costs

The modern conditions predetermine a range of tasks, which educational establishment can fulfil only with the help of advanced information management systems. The need to introduce an ERP-system into management practice of a large university is unquestioned nowadays (Sullivan, 2009; Violino, 2008). The elements of an automatized information management system are now present in almost all universities, though the economic effect of their introduction is in most cases rather low (Xu, Rondeau, \& Mahenthiran, 2011). While earlier the information systems in education attained mostly local goals (particular educational programs in various spheres, accounting, budgeting, personnel registering, etc.), nowadays, with the dynamic social-economic development of educational establishments, the goals are so vast that one cannot afford to distribute the efforts of working groups to different directions of development. Consolidation of the efforts of different department of a university will give a better result, both from the point of view of efficient use of economic resources, and from the point of view of increasing the quality of educational management (Аузан, 2006; Воронцова, Крамин, \& Крамин, 2011; Олейник, 2005).

At present a large number of automatized information management systems for educational establishments are available. However, for a particular university or college, interested in the educational process automatization, the choice of the appropriate model has become even harder. The variety of platforms, of educational models, and developers can baffle even experienced managers of informatization departments. Moreover, the specific of educational activity implies a certain independence of educational establishments, universities in particular. The system should be customized for the specific demands of administration. This significantly complicates the design of the replicated information system and makes its introduction and customization much more expensive for a particular university, college, or school (Jones, 2009).

The work presents the experience of projecting, designing and introducing the information management system of a rapidly developing university with a network of large sustainable branches and a high degree of centralization of managerial functions. Ways of solving problems are proposed ${ }^{1}$.

The goals of the system designing and introducing are defined:

1. Optimization of the functioning of personnel which deals with the educational process (Academic Work Department, Dean's Offices, Admission Department, Educational Methodology Department, Chairs).

2. Accounting of the professors' working time and using these data or detailed calculation of the costs of educational process.

3. Planning and predicting the teaching load in each discipline.

\footnotetext{
1 See also stage of ERP systems development (Esteves \& Pastor, 1999; Sabau, Munten, Bologa, Bologa, \& Surcel, 2009).
} 
4. Making prompt managerial decision (personnel policy, price-forming, planning financial results) at each level.

5. Increasing the efficiency of informational and communicational subsystems of the management system of the educational establishment.

6. Revealing, accounting and minimization of transactional costs (Воронцова et al., 2011; Крамин, 2007a, 2007b).

The software market research by the authors showed that up to date there are no ERP-systems for universities, satisfying the requirements of universality, simplicity of use and economic efficiency (West \& Daigle, 2004). The western products are either not adapted to the Russian legislation or demand introduction expenses of more than $4 \%$ of gross income of the organization during 3 years, while the worldwide practice considers it optimal to spend $3 \%$ for maintenance and development of alit infrastructure, including technical maintenance and servicing. Moreover, each purchase must be grounded. In Russia this indicator is, as a rule, much lower: 0.5\% - 1.5\%.

The Russian software for reasonable prices are either lower in class than ERP-systems, or require significant overpatching for automatization of the business processes of a university. Due to that many Russia universities have faced a dilemma: which is the least evil? To buy a foreign product with a distinct introduction program and tangible result, but with large expenses and complete dependence upon the designers (each change in the legislation will require changes in the system), or a Russian one, which is cheap and easy to use, but in 2-3 you may face the risk of mismatch between the expectations and the results, or, still worse, of disability of the product to fulfil certain tasks.

All these factors prompted Institute of Economics, Management and Law (Kazan) in May 2006 to make a decision to create a special information system, meeting all the necessary requirements. The geographical remoteness of the Institute's subdivisions (7 training and 2 administrative buildings in Kazan, 7 branches in Tatarstan and Chuvash Republic) determined the architecture of the information management systems (IMS) of the Institute. It has a weboriented interface and is based on $1 \mathrm{C}$ and J2EE technologies. The common data network with the branches and the high quality of connection allowed to use one server for accessing the system resources.

As practice shows, universities face significant obstacles in creating their own ERP systems (Carroll, 2009). We concluded that such system cannot be created to a classical pattern "examination-projecting-design-introductionmaintenance", as this cycle can be accomplished not earlier than in 3 years. By that time the project may become obsolete. The technique we used contains the same sequence, but is multi-layered. It means that initially only the general principles and logic of the system are rigidly determined, but the detailing of the system and the "design-introductionmaintenance" stages take place immediately after successful testing of the block, whose output serves as the input of the new block (Fig.1). This approach allowed to introduce the system gradually, without losing control over the general design process. For example, the "Admission Department" block was introduced when the "Students' Progress Registering" was still being designed. By today the whole educational process has been designed; working with the schedule has not been introduced; the systems contains data on all $1^{\text {st }}$ and $2^{\text {nd }}$ year students from the branches.

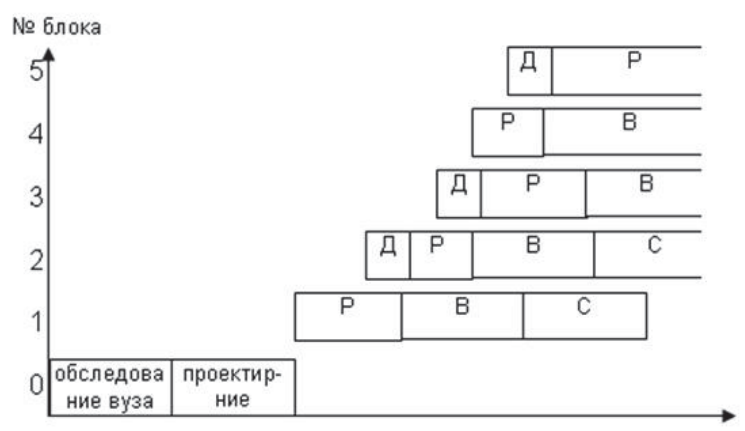

Fig. 1. Pattern of the information system forming. Stage: $\mathrm{Z}$ - detailing, $P$ - design, $B$ - introduction, $C$ - maintenance.

The resource management at an enterprise presupposes accounting of all resources. A university is quite a unique services-rendering organization. By our estimations, costs of salaries of the teaching and administrative staff plus taxes amount to about $70 \%$ of the cost of student's training. That is why these costs require strict accounting. The modern accounting systems allow to successfully register and plan all costs which are not directly connected with educational process. That is why it is necessary, in our opinion, to arrange interaction between IMS and automatized accounting systems. 
Two approaches to this task are defined. First, we can automatize the teaching load accounting through scheduleforming directly in accounting system (обсуждение вопросов внедрения показано в Hepner \& Dickson, 2013; Joseph \& George, 2002; Watson \& Schneider, 1999). Second, we can create a software "superstructure" by different means. In IEML the task was solved initially by the first and then by the second method. To implement the second method, J2EE was used, as there was a requirement of distant working and unlimited scaling.

At present the actual data on the students' contingent and the fulfilled teaching load are systematically transferred from IMS to accounting system, and the data on the personnel - in the opposite direction. Further we are planning to use the change-server to synchronize both systems.

The final result will be a universal system. This is a complicated task, as the decision to create a unique system was made, in particular, with a view of maximal matching to the business processes of our university. The universality (applicability for the tasks of other educational establishments) is achieved by maximal softening the system limitations and using the system of most general assumptions of the functioning conditions.

As a result the main conclusion is made: the independent elaboration and introduction of IMS at university of is possible only under the following conditions:

- Available team of experienced designers, system analysts, specialists in software introduction and staff training;

- The university is developing so fast that the traditional management techniques appear to be inefficient;

- The university actively uses innovations and has know-how in staff management, in working with students, in various kinds of accounting, that is why the available software cannot be adjusted to the changes in the university;

- The university administration at all level should be interested in the result and fully understand the complexity of the work;

The peculiar features of the process of elaboration and introduction of the IMS of an educational establishment are:

- integration with standard variants of automatized accounting systems; the system is a separate configuration and has an open code with detailed description and possibility to overpatching by the user or a third party;

- $\quad$ involving a large scale of specialists: not only programmers and system analysts, but also lecturers, heads of departments, vice-rectors, which allows to completely reflect the details of the educational process in establishments of all levels, all property forms, and technologies in the information system model (Scholtz, Cilliers, \& Calitz, 2012);

- continuous account, implementation and adaptation of new information technologies in education; the work of the new system in correspondence with accounting systems; for example, the model implements the transfer of the "semester" notion to the "studying period" parameter, which increases the model flexibility and allows to use it in schools. The model also involves a flexible format of the assessment scale, which can be adjusted to the one adopted in the educational establishment. Thus the universality and user-attractiveness of the system is increased;

- complete and hierarchical character of the model; the model contains all blocks necessary for the educational process management: admission department, students' contingent, teaching staff, teaching load distribution, schedule forming, load execution, payments; all other blocks are constituent parts of the mentioned modules, grouped in various reports; such a simple structure presupposes the possibility to overpatch and to fulfil all needs of the users.

- The first experience of introducing the elements of information system model shows that:

- it reduces administrative expenses for information flow and document processing, expenses for control over processes and ensures communicative functions;

- it significantly increases the influence of feedback from consumers of educational services to the university administration;

- it stimulates the administration and personnel to constant overpatching the system for the demands of its clients - the students. This fact has a positive effect on their loyalty to the educational establishment, increasing their attendance and progress;

- it increases the openness of the information for students and results in the more disciplined and coordinated work of all structural subdivisions, as any mistake is seen to other users and the competence of the worker can be doubted.

Thus, there are prerequisites for significant reduction of transactional costs of the organization. Moreover, the proposed architecture of the information system model, including the automatized accounting system, allows to promptly 
reveal, estimate and minimize its transactional costs. Consequently, the reduction of transactional costs can be estimated in monetary terms.

In future we intend to develop the complex model of the information system of an educational establishment, as well as to train personnel for complete implementation of its possibilities (Chang \& Chou, 2011; Kerr, Burgess, Houghton, \& Murray, 2012). In this process, efforts of universities should be united in order to create the most high-quality and universal product, as well as to mutually use and improve it.

\section{References}

Carroll, T. D. (2009). ERP Project Management Lessons Learned. Educause Quarterly, 32(2).

Chang, H.-H., \& Chou, H.-W. (2011). Drivers and effects of enterprise resource planning post-implementation learning. Behaviour \& Information Technology, 30(2), 251-259.

Esteves, J., \& Pastor, J. (1999). An ERP lifecycle-based research agenda. Paper presented at the 1st International Workshop in Enterprise Management \& Resource Planning.

Hepner, M., \& Dickson, W. (2013). The Value of ERP Curriculum Integration: Perspectives from the Research. Journal of Information Systems Education, 24(4), 309.

Jones, M. (2009). The Strategic Academic Enterprise: Why ERPs Will No Longer Be Adequate. College and University, 84(4), 55.

Joseph, G., \& George, A. (2002). ERP, learning communities, and curriculum integration. Journal of Information Systems Education, 13(1), 51-58.

Kerr, D., Burgess, K. J., Houghton, L., \& Murray, P. A. (2012). Improving training in enterprise resource planning systems implementation through communities of practice. International Journal of Learning and Change, 6(3), 207-222.

Sabau, G., Munten, M., Bologa, A.-R., Bologa, R., \& Surcel, T. (2009). An evaluation framework for higher education ERP Systems. WSEAS Transactions on Computers, 11(8), 1790-1799.

Scholtz, B., Cilliers, C., \& Calitz, A. (2012). A Comprehensive, Competency-Based Education Framework Using Medium-Sized ERP Systems. Journal of Information Systems Education, 23(4), 345-358.

Sullivan, L. S. (2009). Post-implementation success factors for enterprise resource planning (ERP) student administration systems in higher education institutions: University of Central Florida.

Violino, B. (2008). ERP= Efficiency. Community College Journal, 79(1), 28-30.

Watson, E. E., \& Schneider, H. (1999). Using ERP systems in education. Communications of the AIS, 1(2es), 3.

West, R., \& Daigle, S. L. (2004). Total cost of ownership: A strategic tool for ERP planning and implementation. Philadelphia, PA: Center for Applied Research.

Xu, H., Rondeau, P. J., \& Mahenthiran, S. (2011). The Challenge of Implementing an ERP System in a Small and Medium Enterprise--A Teaching Case of ERP Project Management. Journal of Information Systems Education, 22(4), 291-296.

Nagimova, A.M., Safiullina, F.R. (2014). Combination of university training with employment among Kazan' students. Sotsiologicheskie Issledovaniya, (4), pp. 121-124.

Tsertseil, J.S. The way of clusters uprising and development in the region (By the example of the petrochemical cluster in the republic of Tatarstan). Mediterranean Journal of Social Sciences, Volume 5, Issue 18 SPEC. ISSUE, 2014, Pages 125-128

Safina, D., Podgornaya, A. (2014). Mobbing as an organizational phenomenon impeding implementation of changes. Mediterranean Journal of Social Sciences, 5 (18 SPEC. ISSUE), pp. 187-192. 